\title{
Biology of three species of the Meccus phyllosomus complex (Hemiptera: Reduviidae: Triatominae) fed on blood of hens and rabbits
}

\author{
José Alejandro Martínez-Ibarra/ ${ }^{+}$, Ricardo Alejandre-Aguilar*, Alfredo Torres-Morales, \\ Josefina Cecilia Trujillo-García**, Benjamín Nogueda-Torres*, Francisco Trujillo-Contreras
}

Área de Entomología Médica, Centro Universitario del Sur, Universidad de Guadalajara, A. P. 20, 49000 Ciudad Guzmán, Jalisco, México *Becario de COFAA, Escuela Nacional de Ciencias Biológicas, Instituto Politécnico Nacional, Carpio y Plan de Ayala, Colonia Casco de Santo Tomás, México, D. F. **Sección de Entomología, Laboratorio Estatal de Salud Pública de Oaxaca, Reyes Mantecón, Oaxaca, México

Aspects related to hatching, life time, number of blood meals to molt, mortality, feeding time and postfeed defecation delay for each instar of Meccus phyllosomus, M. mazzottii, and M. bassolsae, life-cycle were evaluated and compared in two cohorts of each of those three species, fed on hens or rabbits. No significant ( $p>0.05)$ differences were recorded among cohorts fed on hens respect to cohorts fed on rabbits in M. phyllosomus and M. mazzottii and the average time of hatching was 21.5 days for cohorts fed on hens and 22.5 for cohorts fed on rabbits. Average egg-to-adult development times were no significant $(p>0.05)$ different between both cohorts of $\mathrm{M}$. phyllosomus and M. mazzotti, independent of the blood meal source. The average span in days for each instar fed on hens was not significantly different to the average span for each instar fed on rabbits, when comparisons were made by species. The number of blood meals at each nymphal instar varied from 1 to 6 in both cohorts of each species. The mortality rates were higher on older nymphs, in both cohorts of $\mathrm{M}$. phyllosomus and $\mathrm{M}$. bassolsae, whereas they were higher on first instar nymphs on M. mazzottii. Mean feeding time was no significant $(p>0.05)$ different in triatomines fed on hens or fed on rabbits, when each species were compared separately. A similar number of nymphs of each cohort, completed the cycle. Defecation delay was no significant $(p>0.05)$ different when cohorts fed on hens and fed on rabbits were compared by species. Most of the studied parameters showed no significant ( $p>0.05)$ differences among those cohorts fed on hens and for fed on rabbits, which could mean a high degree of association of those species with birds as much as mammals, under wild conditions, increasing their capacity to colonize human dwellings.

Key words: Meccus phyllosomus complex - biology - blood source - laboratory conditions

Mexico is one of the American countries with more (34) species of triatomines; among them, all the six species of the Meccus phyllosomus complex [M.pallidipennis Stål, M. longipennis Usinger, $M$. picturatus Usinger, $M$. mazzottii Usinger, M. phyllosomus (Burmeister), and $M$. bassolsae Alejandre-Aguilar, Nogueda-Torres, CortésJiménez, Jurberg, Galvão and Carcavallo], play an important role in the transmission of Trypanosoma cruzi to human populations, because they can be found in both domestic and wild ecotopes, with frequent domiciliated colonies, and they frequently have high entomological indexes, used to monitored the Chagas control programs (Ramsey et al. 2000, Vidal-Acosta et al. 2000, Villegas-García \& Santillán-Alarcón 2001, 2004, Magallón-Gastélum et al. 2004, Enger et al. 2004, Sosa-Jurado et al. 2004, SalazarSchettino et al. 2005). Habits, feeding, and defecation behaviors of $M$. pallidipennis and $M$. longipennis have been extensively studied (Torres-Estrada et al. 1993, MenaSegura et al. 1994, Bautista et al. 1999, Martínez-Ibarra \& Katthain-Duchateau 1999, Martínez-Ibarra et al. 2003a,

${ }^{+}$Corresponding author: aibarra@cusur.udg.mx

Received 5 June 2006

Accepted 13 September 2006
2004, Breniere et al. 2004, Enger et al. 2004, MagallónGastélum et al. 2004, Martínez-Ibarra \& Novelo-López 2004, Sosa-Jurado et al. 2004, Salazar-Schettino et al. 2005). In contrast, those behaviors aspects of $M$. picturatus and M. mazzottii have been only partially studied (RamírezRovelo et al. 1990, Malo et al. 1993, Barbosa-Gómez \& García da Silva 2001, Martínez-Ibarra et al. 2003b, 2005) or remain unknown, as in $M$. phyllosomus and in $M$. bassolsae. In consequence, taking into account the associations of those three last species in natural and artificial environments and previous information on its host preferences, the objective of this study was to determine the influence of the blood meal source on the life-cycle, reproductive development and feeding and defecation behavior of M. phyllosomus, M. mazzottii, and M. bassolsae under laboratory conditions.

\section{MATERIALS AND METHODS}

Laboratory colonies of M. phyllosomus and M. mazzottii established in 2004 from specimens captured in Oaxaca, Mexico were used, whereas a colony of $M$. bassolsae, established in 2004, with specimens originally obtained from Acatlan, Puebla, Mexico, was also used. Colonies were maintained at $27 \pm 1^{\circ} \mathrm{C}$ and $75 \pm 5 \%$ relative humidity (rh) and fed weekly on immobilized Leghorn hens or New Zealand rabbits. 
Eggs of each species were grouped by date of oviposition to initiate two cohorts by species of 200 eggs each. After eclosion, the two groups of each species of firstinstar nymphs were separated individually into plastic containers $(5.5 \mathrm{~cm}$ diameter $\times 10.5 \mathrm{~cm}$ height $)$, with an upcenter support of absorbent cardboard. Three days after eclosion, each cohort of nymphs was individually fed on Leghorn hens or New Zealand rabbits during a $1 \mathrm{~h}$ period, for the subsequent blood meals, they were fed weekly. Nymphs were observed from the beginning of feeding through an hour postfeeding for recording feeding and defecation behaviors. The bugs were maintained in a dark incubator at $27 \pm 1^{\circ} \mathrm{C}$ and $75 \pm 5 \% \mathrm{rh}$, and were checked daily for ecdysis or death.

From the insects that completed development to the adult instar, 10 adult couples of each cohort were placed in individual containers $(5.5 \mathrm{~cm}$ diameter $\times 10.5 \mathrm{~cm}$ height) and maintained as previously described to determine oviposition patterns.

The variables that showed a normal distribution were compared by Student t-test or analysis of variance (ANOVA). In the case of ANOVA tests, post hoc comparisons were made using the Scheffé test. The Wilcoxon nonparametric test was used for variables with a nonnormal distribution. The chi-square test was used for comparison of frequencies. The differences were considered to be significant when $p<0.05$.

\section{RESULTS}

Egg eclosion rate was over $70 \%$ in all cohorts, except on M. bassolsae fed on hen, with averages incubation period slightly above of twenty days for all studied cohorts. No significant $(p>0.05)$ difference was recorded among both cohorts of M. phyllosomus, and similarly, for M. mazzottii $(p>0.05)$. Significant $(p<0.05)$ difference was only recorded among the cohorts of $M$. bassolsae. Significant $(\mathrm{p}<0.05)$ higher egg eclosion rates were recorded for both cohorts of M. mazzotti, when all cohorts were compared (Table I).

Average egg-to-adult development times were no significant ( $\mathrm{p}>0.05)$ different among both cohorts of $M$. phyllosomus and M. mazzotti, independent of the blood meal source. On the other hand, average times of both cohorts of M. bassolsae were no significant ( $p>0.05$ ) different one to each other, but they were significant $(\mathrm{p}<$ 0.05 ) higher than those for the other studied species (Tables II, III).

Average numbers of blood meals to molt to next instar were no significant $(\mathrm{p}>0.05)$ different between both cohorts of M. phyllosomus, and between them and the cohorts of M. mazzottii fed on hens and that of M. bassolsae fed on rabbits. On the other hand, both cohorts of $M$. mazzottii and both of $M$. bassolsae were no significant ( $\mathrm{p}$ $>0.05$ ) different one to each other, independent of the blood meal source (Tables IV, V).

Mortality rates were no significant $(p>0.05)$ different among both cohorts of $M$. mazzottii but they were significant $(\mathrm{p}<0.05)$ lower than those for remain four studied cohorts. On the other and, both cohorts of $M$. phyllosomus, and the one of M. bassolsae fed on hens had medium (from 45 to almost $60 \%$ ) mortality rates, significant $(\mathrm{p}<0.05)$ different of the high mortality rate $(78.6 \%)$ of the cohort of M. bassolsae fed on rabbits (Tables VI and VII). A no significant ( $p>0.05$ ) different number of females and males of each studied cohort of each species was obtained (Table VIII).

TABLE I

Egg eclosion rate and average incubation period for Meccus phyllosomus, M. mazzottii, and M. bassolsae fed every seven days on hens or rabbits

\begin{tabular}{lccccr}
\hline \multirow{2}{*}{ Species } & \multicolumn{2}{c}{ Egg eclosion rate (\%) } & & \multicolumn{2}{c}{$\begin{array}{c}\text { Average incubation period (in days) } \\
\text { (range on parenthesis) }\end{array}$} \\
\cline { 2 - 3 } M. phyllosomus & Hen & Rabbit & & Hen & Rabbit \\
\hline M. mazzotti & 82 & 70 & & $21.5(18-24)$ & $21.7(17-23)$ \\
M. bassolsae & 99.5 & 92 & & $22.2(18-25)$ & $23.1(17-24)$ \\
\hline
\end{tabular}

TABLE II

Egg to adult development cycle of Meccus phyllosomus, M. mazzottii, and M. bassolsae fed every seven days on hens

\begin{tabular}{|c|c|c|c|c|c|c|}
\hline \multirow[b]{3}{*}{ Instar } & \multicolumn{6}{|c|}{ Duration in days } \\
\hline & \multicolumn{2}{|c|}{ M. phyllosomus } & \multicolumn{2}{|c|}{ M. mazzotti } & \multicolumn{2}{|c|}{ M. bassolsae } \\
\hline & $\mathrm{Nr}$ & Mean \pm SD & $\mathrm{Nr}$ & Mean \pm SD & $\mathrm{Nr}$ & Mean \pm SD \\
\hline Egg-NI & 164 & $19.4 \pm 0.7$ & 199 & $20.4 \pm 5.7$ & 107 & $21.7 \pm 7.9$ \\
\hline NI-NII & 150 & $26.1 \pm 8.9$ & 164 & $32.4 \pm 17.8$ & 91 & $26.9 \pm 6.3$ \\
\hline NII-NIII & 148 & $24.5 \pm 4.2$ & 159 & $39.8 \pm 13.2$ & 88 & $32.5 \pm 13.1$ \\
\hline NIII-NIV & 138 & $32.1 \pm 16.9$ & 155 & $37.6 \pm 9.8$ & 79 & $48.6 \pm 71.1$ \\
\hline NIV-NV & 108 & $57.8 \pm 14.6$ & 154 & $31.3 \pm 8.9$ & 66 & $61.9 \pm 22.5$ \\
\hline NV-AD & 94 & $62.9 \pm 11.8$ & 145 & $51.7 \pm 15.5$ & 41 & $70.4 \pm 21.7$ \\
\hline Total & 94 & $192.6 \pm 22.7$ & 145 & $191.7 \pm 22.8$ & 41 & $242.7 \pm 54.6$ \\
\hline
\end{tabular}


TABLE III

Egg to adult development cycle of Meccus phyllosomus, M. mazzottii, and M. bassolsae fed every seven days on rabbits

\begin{tabular}{|c|c|c|c|c|c|c|}
\hline \multirow[b]{3}{*}{ Instar } & \multicolumn{5}{|c|}{ Duration in days } & \\
\hline & \multicolumn{2}{|c|}{ M. phyllosomus } & \multicolumn{2}{|c|}{ M. mazzotti } & \multicolumn{2}{|c|}{ M. bassolsae } \\
\hline & $\mathrm{Nr}$ & Mean $\pm \mathrm{SD}$ & $\mathrm{Nr}$ & Mean $\pm \mathrm{SD}$ & $\mathrm{Nr}$ & Mean \pm SD \\
\hline Egg-NI & 140 & $19.7 \pm 1.1$ & 194 & $24.3 \pm 8.6$ & 157 & $22.4 \pm 6.9$ \\
\hline NI-NII & 136 & $20.4 \pm 7.1$ & 167 & $20.4 \pm 0.9$ & 126 & $39.9 \pm 11.5$ \\
\hline NII-NIII & 134 & $20.7 \pm 4.7$ & 157 & $31.2 \pm 1.4$ & 102 & $54.2 \pm 21.8$ \\
\hline NIII-NIV & 126 & $37.6 \pm 18.1$ & 154 & $32.8 \pm 1.8$ & 92 & $66.2 \pm 28.3$ \\
\hline NIV-NV & 104 & $51.9 \pm 13.3$ & 152 & $40.4 \pm 0.9$ & 84 & $53.5 \pm 26.5$ \\
\hline NV-AD & 86 & $77.8 \pm 8.2$ & 143 & $59.1 \pm 1.6$ & 66 & $55.7 \pm 20.2$ \\
\hline Total & 86 & $176.8 \pm 34.8$ & 143 & $201.9 \pm 9.7$ & 66 & $270.5 \pm 44.0$ \\
\hline
\end{tabular}

TABLE IV

Number of blood meals for Meccus phyllosomus, M. mazzottii, and M. bassolsae fed every seven days on hens under laboratory conditions

\begin{tabular}{|c|c|c|c|c|c|c|}
\hline \multirow[b]{2}{*}{ Instar } & \multicolumn{2}{|c|}{ M. phyllosomus } & \multicolumn{2}{|c|}{ M. mazzotti } & \multicolumn{2}{|c|}{ M. bassolsae } \\
\hline & $\begin{array}{c}\mathrm{Nr} \text { of } \\
\text { nymphs }\end{array}$ & $\begin{array}{c}\text { Nr blood meals } \\
\text { Mean } \pm \text { SD }\end{array}$ & $\begin{array}{l}\text { Nr of } \\
\text { nymphs }\end{array}$ & $\begin{array}{l}\text { Nr blood meals } \\
\text { Mean } \pm \text { SD }\end{array}$ & $\begin{array}{l}\text { Nr of } \\
\text { nymphs }\end{array}$ & $\begin{array}{c}\text { Nr blood meals } \\
\text { Mean } \pm \text { SD }\end{array}$ \\
\hline I & 164 & $1.1 \pm 0.1$ & 199 & $1.2 \pm 0.3$ & 107 & $2.9 \pm 0.9$ \\
\hline II & 150 & $1.4 \pm 0.5$ & 164 & $1.6 \pm 1.1$ & 91 & $1.5 \pm 0.5$ \\
\hline III & 148 & $1.1 \pm 0.1$ & 159 & $1.7 \pm 0.7$ & 88 & $1.5 \pm 0.6$ \\
\hline IV & 138 & $1.6 \pm 0.6$ & 155 & $1.9 \pm 0.6$ & 79 & $1.8 \pm 0.7$ \\
\hline $\mathrm{V}$ & 108 & $1.9 \pm 0.7$ & 154 & $2.4 \pm 1.1$ & 66 & $2.2 \pm 1.0$ \\
\hline Total & 94 & $6.7 \pm 1.2$ & 145 & $8.4 \pm 1.5$ & 41 & $9.6 \pm 1.4$ \\
\hline
\end{tabular}

TABLE V

Number of blood meals for Meccus phyllosomus, M. mazzottii, and M. bassolsae fed every seven days on rabbits under laboratory conditions

\begin{tabular}{|c|c|c|c|c|c|c|}
\hline \multirow[b]{2}{*}{ Instar } & \multicolumn{2}{|c|}{ M.phyllosomus } & \multicolumn{2}{|c|}{ M. mazzotti } & \multicolumn{2}{|c|}{ M. bassolsae } \\
\hline & $\begin{array}{c}\mathrm{Nr} \text { of } \\
\text { nymphs }\end{array}$ & $\begin{array}{c}\text { Nr blood meals } \\
\text { Mean } \pm \text { SD }\end{array}$ & $\begin{array}{l}\mathrm{Nr} \text { of } \\
\text { nymphs }\end{array}$ & $\begin{array}{c}\text { Nr blood meals } \\
\text { Mean } \pm \text { SD }\end{array}$ & $\begin{array}{l}\mathrm{Nr} \text { of } \\
\text { nymphs }\end{array}$ & $\begin{array}{c}\text { Nr blood meals } \\
\text { Mean } \pm \text { SD }\end{array}$ \\
\hline I & 140 & $1.2 \pm 1.3$ & 194 & $1.4 \pm 0.2$ & 157 & $1.6 \pm 0.4$ \\
\hline II & 136 & $1.2 \pm 0.4$ & 167 & $1.5 \pm 0.3$ & 126 & $1.5 \pm 0.6$ \\
\hline III & 134 & $1.1 \pm 0.3$ & 157 & $2.2 \pm 0.7$ & 102 & $1.9 \pm 0.8$ \\
\hline IV & 126 & $1.5 \pm 0.6$ & 154 & $2.2 \pm 0.5$ & 92 & $1.8 \pm 0.4$ \\
\hline $\mathrm{V}$ & 104 & $1.6 \pm 0.6$ & 152 & $3.3 \pm 0.2$ & 84 & $1.9 \pm 0.4$ \\
\hline Total & 86 & $6.2 \pm 1.2$ & 143 & $10.2 \pm 0.8$ & 66 & $8.4 \pm 1.3$ \\
\hline
\end{tabular}

TABLE VI

Instar mortality for Meccus phyllosomus, M. mazzottii, and M. bassolsae fed on hens under laboratory conditions

\begin{tabular}{|c|c|c|c|c|c|c|}
\hline \multirow[b]{2}{*}{ Instar } & \multicolumn{2}{|c|}{ M. phyllosomus } & \multicolumn{2}{|c|}{ M. mazzotti } & \multicolumn{2}{|c|}{ M. bassolsae } \\
\hline & Nr nymphs & $\%$ mortality & Nr nymphs & $\%$ mortality & Nr nymphs & $\%$ mortality \\
\hline I & 164 & 8.5 & 199 & 12.6 & 107 & 15.0 \\
\hline II & 150 & 1.3 & 164 & 3.1 & 91 & 3.3 \\
\hline III & 148 & 6.7 & 159 & 2.5 & 88 & 10.2 \\
\hline IV & 138 & 21.7 & 155 & 0.7 & 79 & 16.5 \\
\hline $\mathrm{V}$ & 108 & 12.9 & 154 & 5.8 & 66 & 12.5 \\
\hline Total & 94 & $(51.3)$ & 145 & $(24.7)$ & 41 & $(57.5)$ \\
\hline
\end{tabular}


TABLE VII

Instar mortality for Meccus phyllosomus, M. mazzottii, and M. bassolsae fed on rabbits under laboratory conditions

\begin{tabular}{|c|c|c|c|c|c|c|}
\hline \multirow[b]{2}{*}{ Instar } & \multicolumn{2}{|c|}{ M. phyllosomus } & \multicolumn{2}{|c|}{ M. mazzotti } & \multicolumn{2}{|c|}{ M. bassolsae } \\
\hline & $\mathrm{Nr}$ nymphs & $\%$ mortality & Nr nymphs & $\%$ mortality & $\mathrm{Nr}$ nymphs & $\%$ mortality \\
\hline I & 140 & 2.9 & 194 & 13.9 & 157 & 19.7 \\
\hline II & 136 & 1.5 & 167 & 6.0 & 126 & 19.0 \\
\hline III & 134 & 5.9 & 157 & 1.9 & 102 & 9.8 \\
\hline IV & 126 & 17.5 & 154 & 1.3 & 92 & 8.7 \\
\hline $\mathrm{V}$ & 104 & 17.3 & 152 & 5.9 & 84 & 21.4 \\
\hline Total & 86 & $(45.1)$ & 143 & $(29.0)$ & 66 & $(78.6)$ \\
\hline
\end{tabular}

TABLE VIII

Feeding times (min) for Meccus phyllosomus, M. mazzottii, and M. bassolsae fed on hens under laboratory conditions

\begin{tabular}{|c|c|c|c|c|c|c|}
\hline \multirow[b]{2}{*}{ Instar } & \multicolumn{2}{|c|}{ M.phyllosomus } & \multicolumn{2}{|c|}{ M. mazzotti } & \multicolumn{2}{|c|}{ M. bassolsae } \\
\hline & Nr nymphs & Feeding times & Nr nymphs & Feeding times & Nr nymphs & Feeding times \\
\hline I & 164 & $12.7 \pm 2.5$ & 199 & $26.6 \pm 1.1$ & 107 & $19.4 \pm 5.4$ \\
\hline II & 150 & $11.7 \pm 3.8$ & 164 & $22.1 \pm 0.9$ & 91 & $16.9 \pm 6.8$ \\
\hline III & 148 & $8.1 \pm 2.8$ & 159 & $23.5 \pm 0.9$ & 88 & $18.7 \pm 6.3$ \\
\hline IV & 138 & $10.6 \pm 5.5$ & 155 & $27.6 \pm 0.6$ & 79 & $17.4 \pm 5.4$ \\
\hline $\mathrm{V}$ & 108 & $14.5 \pm 8.1$ & 154 & $29.4 \pm 0.5$ & 66 & $19.3 \pm 6.5$ \\
\hline Female & 57 & $18.7 \pm 4.4$ & 74 & $25.0 \pm 0.7$ & 21 & $21.8 \pm 5.4$ \\
\hline Male & 51 & $20.4 \pm 3.3$ & 71 & $28.7 \pm 0.4$ & 20 & $19.4 \pm 6.7$ \\
\hline
\end{tabular}

No significant $(\mathrm{p}>0.05)$ difference was noticed when mean feeding times of every single instar of both cohorts of each species (fed on hens vs fed on rabbits) were compared. It was also recorded no significant $(p>0.05)$ difference in $M$. mazzottii and $M$. bassolsae when all seven instars where compared among them by cohort, however, in M. phyllosomus it was recorded a significant $(\mathrm{p}<0.05)$ difference among most nymphal instars and adults (Tables VIII, IX).

Postfeed defecation delay was under ten minutes in both cohorts of M. mazzottii and in both of M. bassolsae, independent of the blood meal source. No significant ( $\mathrm{p}>$ 0.05 ) difference was recorded with those four average times were recorded. Times for both cycles of $M$. phyllosomus were significant $(\mathrm{p}<0.05)$ longer than those four for two remaining species (Tables X, XI).

\section{DISCUSSION}

Most of the time, it is really different to do a valid comparison between development times and some other related biological parameters about different species of triatomines, because they usually were grown under different laboratory conditions. However, it is possible to arrive to valid conclusions when methodologies and conditions are very similar. Some authors (Juarez 1970, Diotaiuti \& Dias 1987, Lima-Gomes et al. 1990, Braga et al. 1998, Guarneri et al. 2000a, b) have published that the life cycle of at least seven Triatominae species were shorter on cohorts reared on mammals (mice) than on those reared on birds (chicken, pigeons or hens). However, the only two published researches about Meccus species ( $M$. picturatus and $M$. longipennis), report no significant ( $\mathrm{p}>$ $0.05)$ difference when cohorts fed on hens and fed on rabbits or fed on rats were compared (Martínez-Ibarra et al. 2003a, 2004). In the current study, the average development time of the cohorts of $M$. phyllosomus fed on hens (192.6 \pm 22.7 days) and fed on rabbits $(176.8 \pm 34.8$ days) was not significant ( $\mathrm{p}>0.05)$ different among both cohorts, and similarly, M. mazzottii ( $\mathrm{p}>0.05)$, fed on hens $(191.7 \pm 22.8)$ and fed on rabbits $(201.9 \pm 9.7)$, and $M$. bassolsae fed on hens $(242.7 \pm 54.6)$ and fed on rabbits $(270.5 \pm 44.0)$. These results could be expected, based on previous accounts of the natural association of these species with chicken and hens as much as with rodents on the wild of the same geographic area of Mexico (Magallón-Gastélum et al. 1998, Alejandre-Aguilar et al. 1999, Ramsey et al. 2000).

Average development time of the cohorts of $M$. phyllosomus and M. mazzottii fed on hens and fed on rabbits from the current study were compared to previous studies where some cohorts of Meccus species were reared under similar laboratory conditions. Average development time for M. phyllosomus and M. mazzottii was shorter than $M$. longipennis and $M$. mazzottii, similar to $M$. picturatus and longer than M. pallidipennis. Meanwhile, the average development time of $M$. bassolsae was similar to M. longipennis and M. mazzottii, and longer than M. picturatus and M. pallidipennis (Malo et al. 1993, Martínez-Ibarra et al. 2003b, 2004, 2005, Martínez-Ibarra \& Novelo-López 2004).

Many authors report egg hatching rates in Triatominae species above 80\% (Zeledón et al. 1970, Rabinovich 1972, 
TABLE IX

Feeding times for Meccus phyllosomus, M. mazzottii, and M. bassolsae fed on rabbits under laboratory conditions

\begin{tabular}{|c|c|c|c|c|c|c|}
\hline \multirow[b]{2}{*}{ Instar } & \multicolumn{2}{|c|}{ M.phyllosomus } & \multicolumn{2}{|c|}{ M. mazzotti } & \multicolumn{2}{|c|}{ M. bassolsae } \\
\hline & $\mathrm{Nr}$ nymphs & Feeding times & $\mathrm{Nr}$ nymphs & Feeding times & $\mathrm{Nr}$ nymphs & Feeding times \\
\hline I & 140 & $11.2 \pm 1.2$ & 194 & $24.6 \pm 0.9$ & 157 & $21.4 \pm 7.2$ \\
\hline II & 136 & $10.8 \pm 3.3$ & 167 & $20.1 \pm 0.7$ & 126 & $18.4 \pm 6.4$ \\
\hline III & 134 & $7.2 \pm 3.6$ & 157 & $22.5 \pm 0.8$ & 102 & $17.9 \pm 6.5$ \\
\hline IV & 126 & $7.9 \pm 3.6$ & 154 & $26.7 \pm 0.4$ & 92 & $18.2 \pm 6.5$ \\
\hline V & 104 & $11.8 \pm 5.8$ & 152 & $28.4 \pm 0.3$ & 84 & $21.3 \pm 5.5$ \\
\hline Female & 44 & $19.8 \pm 6.6$ & 73 & $24.0 \pm 0.5$ & 36 & $23.8 \pm 6.7$ \\
\hline Male & 42 & $21.6 \pm 4.3$ & 70 & $26.7 \pm 0.1$ & 30 & $22.5 \pm 6.9$ \\
\hline
\end{tabular}

TABLE X

Defecation times (min) for Meccus phyllosomus, M. mazzottii, and M. bassolsae fed on hens under laboratory conditions

\begin{tabular}{|c|c|c|c|c|c|c|}
\hline \multirow[b]{2}{*}{ Instar } & \multicolumn{2}{|c|}{ M. phyllosomus } & \multicolumn{2}{|c|}{ M. mazzotti } & \multicolumn{2}{|c|}{ M. bassolsae } \\
\hline & $\mathrm{Nr}$ nymphs & Defecation time & Nr nymphs & Defecation time & Nr nymphs & Defecation time \\
\hline I & 164 & $22.0 \pm 6.18$ & 199 & $11.4 \pm 0.5$ & 107 & $2.24 \pm 0.3$ \\
\hline II & 150 & $22.6 \pm 10.1$ & 164 & $7.1 \pm 0.7$ & 91 & $2.0 \pm 0.4$ \\
\hline III & 148 & $15.7 \pm 12.8$ & 159 & $8.1 \pm 0.6$ & 88 & $1.7 \pm 0.4$ \\
\hline IV & 138 & $14.1 \pm 12.4$ & 155 & $3.5 \pm 0.5$ & 79 & $1.9 \pm 0.4$ \\
\hline $\mathrm{V}$ & 108 & $20.2 \pm 13.7$ & 154 & $2.6 \pm 0.9$ & 66 & $1.6 \pm 0.2$ \\
\hline Female & 57 & $22.7 \pm 18.4$ & 74 & $5.8 \pm 1.1$ & 21 & $3.2 \pm 3.5$ \\
\hline Male & 51 & $23.5 \pm 19.6$ & 71 & $6.9 \pm 0.4$ & 20 & $4.1 \pm 3.8$ \\
\hline
\end{tabular}

TABLE XI

Defecation times for Meccus phyllosomus, M. mazzottii, and M. bassolsae fed on rabbits under laboratory conditions

\begin{tabular}{|c|c|c|c|c|c|c|}
\hline \multirow[b]{2}{*}{ Instar } & \multicolumn{2}{|c|}{ M. phyllosomus } & \multicolumn{2}{|c|}{ M. mazzotti } & \multicolumn{2}{|c|}{ M. bassolsae } \\
\hline & $\mathrm{Nr}$ nymphs & Defecation time & $\mathrm{Nr}$ nymphs & Defecation time & Nr nymphs & Defecation time \\
\hline I & 140 & $24.1 \pm 7.1$ & 194 & $10.7 \pm 0.3$ & 157 & $1.9 \pm 0.7$ \\
\hline II & 136 & $23.7 \pm 2.5$ & 167 & $6.7 \pm 0.6$ & 126 & $1.7 \pm 0.4$ \\
\hline III & 134 & $12.1 \pm 11.0$ & 157 & $7.9 \pm 0.4$ & 102 & $1.6 \pm 0.3$ \\
\hline IV & 126 & $13.4 \pm 11.7$ & 154 & $3.7 \pm 0.4$ & 92 & $1.8 \pm 0.4$ \\
\hline V & 104 & $19.8 \pm 10.2$ & 152 & $2.2 \pm 0.6$ & 84 & $1.9 \pm 0.4$ \\
\hline Female & 44 & $23.2 \pm 17.3$ & 73 & $5.5 \pm 0.9$ & 36 & $3.4 \pm 3.3$ \\
\hline Male & 42 & $24.2 \pm 12.4$ & 70 & $7.3 \pm 0.4$ & 30 & $4.3 \pm 3.6$ \\
\hline
\end{tabular}

Zárate 1983, Braga et al. 1998, Cabello \& Lizano 2001, Barbosa-Gomes \& Garcia-da Silva 2001, Martínez-Ibarra et al. 2005). However, some studies about the $M$. phyllosomus complex have shown that even when some of these species ( $M$. longipennis, $M$. picturatus) usually have egg hatching rates only slightly below to $80 \%$ (Martínez-Ibarra et al. 2003a, b, 2004), some other species of the complex (M. pallidipennis, M. mazzottii) have had lower egg hatching rates, even under 60\%, $M$. pallidipennis) depending on maintenance conditions (Malo et al. 1993, Martínez-Ibarra \& Katthain-Duchateau 1999, Martínez-Ibarra \& Novelo-López 2004, MartínezIbarra et al. 2005). Egg hatching rates above $90 \%$ in both cohorts of $M$. mazzottii on this current study, as well as egg hatching close to $80 \%$ on $M$. phyllosomus fed on hens and $M$. bassolsae fed on rabbits reflects how favorable were maintenance conditions for the proper development of triatomines.
On average, approximately $75 \%$ of I-IV instars, and $50 \%$ of $\mathrm{V}$ instar of both cohorts of $M$. phyllosomus required one and a half meals in order to molt to the next instars, whereas that percentages of both cohorts of $M$. mazzottii and of $M$. bassolsae required two and a half meals in order to molt to the next instars. Required number of blood meals to molt was similar to those required by other species of the $M$. phyllosomus complex, as $M$. longipennis, M. picturatus, $M$. pallidipennis, and $M$. mazzottii, maintained at similar conditions of temperature and humidity (Martínez-Ibarra et al. 2003a, b, 2004, 2005, Martínez-Ibarra \& Novelo-López 2004). No significant ( $p>0.05)$ differences were noticed when both cohorts of $M$. phyllosomus were compared among them, or both cohorts of M. mazzotti were compared one to each other or when both cohorts of $M$. bassolsae were compared among them. Slightly differences were recorded when cohorts of different species, fed on the same blood meal source 
were compared.

As for some other related species (M. longipennis, $M$. picturatus, $M$. pallidipennis), instar mortality on studied species had an irregular pattern (Martínez-Ibarra et al. 2003a, b, 2004, Martínez-Ibarra \& Novelo-López 2004). Mortality in the youngest nymphs apparently was due to the incapacity of feeding by insects, since dead triatomines were found generally without significant intestinal content. On the other hand, mortality on older nymphs seems to be during their molting. No significant $(\mathrm{p}>0.05)$ differences were recorded on the mortality rates when both cohorts of $M$. phyllosomus were compared among them, or when both cohorts of $M$. mazzotii were compared among them. Similarity on mortality rates among two cohorts of the same species fed on different blood meal sources was also observed on Triatoma pseudomaculata and T. sordida fed on pigeons and mice (Guarneri et al. 2000a, b), $M$. picturatus fed on hens and rabbits (Martínez-Ibarra et al. 2003b) and in M. longipennis fed on hens and rats (Martínez-Ibarra et al. 2004).

On the other hand, significant $(\mathrm{p}<0.05)$ differences were recorded among cohorts fed on hens and that fed on rabbits in $M$. bassolsae. Significant $(\mathrm{p}<0.05)$ differences were noticed between both cohorts of $M$. phyllosomus and the cohort of M. bassolsae fed on hens respect to both cohorts of $M$. mazzottii. The cohort of M. bassolsae fed on rabbits was significant $(\mathrm{p}<0.05)$ different from remain five studied cohorts. Mortality rates in both cohorts of M. phyllosomus and M. bassolsae of this study were significantly $(\mathrm{p}<0.05)$ higher than for other Mexican Triatominae species, such as T. barberi (Zárate 1983, Martínez-Ibarra et al. 2005), M. mazzottii (Malo et al. 1993), M. pallidipennis (Martínez-Ibarra \& Katthain-Duchateau 1999), M. dimidiatus (Martínez-Ibarra et al. 2001), but mortality rates in both cohorts of $M$. phyllosomus and in the cohort of $M$. bassolsae fed on hens were according to most published data for some other species of the $M$. phyllosomus complex, as for $M$. pallidipennis, $M$. longipennis and M. mazzottii (Martínez-Ibarra \& NoveloLópez 2004, Martínez-Ibarra et al. 2004, 2005).

Mean feeding time was no significantly $(p>0.05)$ different when cohorts were compared by species (cohort fed on hens vs cohort fed on rabbits); they seemed not to be influenced by differences in the haemostatic mechanisms of birds and mammals, as Lehane (1991) reported. Both cohorts of $M$. mazzottii required longer time for engorging than both cohorts of $M$. bassolsae and both of M. phyllosomus, which required the shortest period of time. As well as mortality rates, all mean feeding time of the two cohorts of each of three studied species could be framed among published data for some other species of the $M$. phyllosomus complex, as for M. longipennis, $M$. picturatus, $M$. mazzottii in a previous study, and $M$. pallidipennis (Martínez-Ibarra et al 2003a, b, 2005, Martínez-Ibarra \& Novelo-López 2004), all considered as important vectors of $T$. cruzi to human populations in Mexico.

Mean defecation delay was not significant $(p>0.05)$ different when cohorts fed on hens and fed on rabbits were compared. It was neither noticed any significant $(p>$
$0.05)$ difference among both cohorts of $M$. mazzottii and both cohorts of $M$. bassolsae, independent of blood meal source. On the other hand, both cohorts of M. mazzottii and both cohorts of $M$. bassolsae took significant ( $\mathrm{p}<$ 0.05 ) longer periods of time to defecate than both cohorts of $M$. phyllosomus.

According to Zeledón et al. (1977) those species that defecate in the first 5 to 10 min after feeding could be considered potentially effective transmitters of T. cruzi to hosts, since they proposed that triatomines are usually in contact with their host at least that period of time. Taking in account that consideration, $M$. mazzottii as well as $M$. bassolsae could be considered as effective transmitters of T. cruzi as T. infestans, Rhodnius prolixus, T. rubida sonoriana, nymphs of T. rubrovaria (Pippin 1970, Zeledón et al. 1977, Almeida et al. 2005, Martínez-Ibarra et al 2005) and some related species of the $M$. phyllosomus complex, as $M$. longipennis, $M$. picturatus, $M$. mazzottii in a previous study, and M. pallidipennis (Martínez-Ibarra et al 2003a, b, 2005, Martínez-Ibarra \& Novelo-López 2004).

Most of the studied parameters showed no significant $(p>0.05)$ differences among those cohorts fed on hens and for fed on rabbits, reflecting the possible association of those three studied species to mammals as much as to birds in wild ecotopes, which could facilitate their colonization of human dwellings in their distribution area. Results on the studied parameters added to the above facts, lead us to conclude, as suggested by previous field studies (Magallón-Gastélum et al. 1998, Alejandre-Aguilar et al. 1999, Ramsey et al. 2000), that M. phyllosomus, $M$. mazzottii, and $M$. bassolsae could be considered important potential vectors of $T$. cruzi to human population in those areas of Mexico where they are currently present.

\section{ACKNOWLEDGEMENTS}

To Jorge Alejandro Martínez-Grant for help in the development of this study.

\section{REFERENCES}

Alejandre-Aguilar R, Nogueda-Torres B, Cortés-Jiménez M, Jurberg J, Galvão C, Carcavallo R 1999. Triatoma bassolsae sp. no Mexico, com uma chave para as espécies do complexo "phyllosoma" (Hemiptera: Reduviidae). Mem Inst Oswaldo Cruz 94: 353-359.

Almeida CE, Folly-Ramos E, Agapito-Souza R, Magno-Esperança, Pacheco RS, Costa J 2005. Triatoma rubrovaria (Blanchart, 1843) (Hemiptera-Reduviidae-Triatominae) IV: bionomic aspects on the vector capacity of nymphs. Mem Inst Oswaldo Cruz 100: 231-235.

Barbosa-Gomes A, García da Silva I 2001. Influência da temperature na biologia de triatomíneos. XXII Triatoma picturata Usinger, 1939 (Hemiptera: Reduviidae). Entomol Vect 8: 217-228.

Bautista NL, García de la Torre GS, De Haro I, Salazar-Schettino PM 1999. Importance of Triatoma pallidipennis (Hemiptera: Reduviidae) as a vector of Trypanosoma cruzi (Kinetoplastida: Trypanosomatidae) in the state of Morelos, Mexico and possible ecotopes. J Med Entomol 36: 233235.

Braga MV, Pinto ZT, Lima MM 1998. Life cycle and reproductive patterns of Triatoma rubrofasciata (De Geer, 1773) 
(Hemiptera: Reduviidae), under laboratory conditions. Mem Inst Oswaldo Cruz 93: 539-542.

Breniere SF, Pietrokovsky S, Magallón-Gastélum E, Bosseno MF, Soto MM, Ouaissi A, Lozano-Kasten F, Wisnivesky-Colli C 2004. Feeding patterns of Triatoma longipennis Usinger (Hemiptera: Reduviidae) in peridomestic habitats of a rural community in Jalisco state, Mexico. J Med Entomol 41: 10151020 .

Cabello DR, Lizano E 2001. Biology of Triatoma flavida Neiva 1911 (Hemiptera: Reduviidae) under laboratory conditions. Mem Inst Oswaldo Cruz 96: 879-882.

Diotaiuti L, Dias JCP 1987. Estudo comparativo do ciclo evolutivo do Rhodnius neglectus alimentados em pombos ou camundongos. Rev Soc Bras Med Trop 20: 95-100.

Enger KS, Ordoñez R, Wilson ML, Ramsey JM 2004. Evaluation of risk factors for rural infestation by Triatoma pal-lidipenis (Hemiptera: Triatominae) a Mexican vector of Chagas disease. J Med Entomol 41: 760-767

Guarneri AA, Pereira MH, Diotaiuti L 2000a. Influence of the blood meal source on the development of Triatoma infestans, Triatoma brasiliensis, Triatoma sordida, and Triatoma pseudomaculata (Heteroptera, Reduviidae). J Med Entomol 37: 373-379.

Guarneri AA, Diotaiuti L, Gontijo NF, Gontijo AF, Pereira MH 2000b. Comparison of feeding behaviour of Triatoma infestans, Triatoma brasiliensis and Triatoma pseudomaculata in different host by electronic monitoring of the cibarial pump. J Insect Physiol 46: 1121-1127.

Juarez E 1970. Comportamento do Triatoma infestans sob várias condições de laboratório. Rev Saúde Públ 4: 147-166.

Lehane MJ 1991. Biology of Blood-Sucking Insects, Harper Collins Academic, London, 427 pp.

Lima-Gomes JE, Azambuja P, Garcia ES 1990. Comparative studies on the growth and reproductive performances of Rhodnius prolixus reared on different blood sources. Mem Inst Oswaldo Cruz 85: 299-304.

Magallón-Gastélum E, Magdaleno-Peñaloza NC, KatthainDuchateau G, Trujillo-Contreras F, Lozano-Kasten FJ, Hernández-Gutiérrez R 1998. Distribución de los vectores de la enfermedad de Chagas (Hemiptera: Reduviidae: Triatominae), en el estado de Jalisco, México. Rev Biomed 9: 151-157.

Magallón-Gastélum E, Lozano-Kasten F, Bosseno MF, CárdenasContreras R, Ouaissi A, Breniere SF 2004. Colonization of rock pile boundary walls in fields by sylvatic Triatomines (Hemiptera: Reduviidae) in Jalisco state, Mexico. J Med Entomol 41: 484-488.

Malo EA, Ramírez-Novelo A, Cruz-López L, Rojas JC 1993. Life cycle and influence of age and feeding on the first mating of Triatoma mazzottii (Hemiptera: Reduviidae). Mem Inst Oswaldo Cruz 88: 203-206.

Martínez-Ibarra JA, Katthain-Duchateau G 1999. Biology of Triatoma pallidipennis (Hemiptera: Reduviidae) under laboratory conditions. Mem Inst Oswaldo Cruz 94: 837-839.

Martínez-Ibarra JA, Novelo-López M 2004. Biological parameters of Triatoma pallidipennis Stal (Hemiptera: Reduviidae) under laboratory conditions. Folia Entomol Mex 43: 313-319.
Martínez-Ibarra JA, Grant-Guillén Y, Martínez-Grant DM 2003a. Feeding, defecation and development times of Meccus longipennis Usinger 1939 (Hemiptera: Reduviidae: Triatominae) under laboratory conditions. Mem Inst Oswaldo Cruz 98: 899-903.

Martínez-Ibarra JA, Grant-Guillén Y, Nogueda-Torres B, TrujilloContreras F 2004. Influence of the blood meal source on the biology of Meccus longipennis Usinger 1939 (Hemiptera: Reduviidae) under laboratory conditions. J Am Mosq Cont Assoc 20: 328-330.

Martínez-Ibarra JA, Novelo-López M, Hernández-Robles MR, Grant-Guillén Y 2003b. Influence of the blood meal source on the biology of Meccus picturatus Usinger 1939 (Hemiptera: Reduviidae: Triatominae) under laboratory conditions. Mem Inst Oswaldo Cruz 98: 227-232.

Martínez-Ibarra JA, Miguel-Álvarez A, Arredondo-Jiménez JI, Rodríguez-López MH 2001. Update on the biology of Triatoma dimidiata Latreille (Hemiptera: Reduviidae) under laboratory conditions. J Am Mosq Cont Assoc 17: 209-210.

Martínez-Ibarra JA, Nogueda-Torres B, Paredes González E, Alejandre-Aguilar R, Solorio-Cibrián M, Barreto SP, GómezEstrada HI, Trujillo-García JC 2005. Development of Triatoma rubida sonoriana, Triatoma barberi, and Meccus mazzottii (Heteroptera, Reduviidae) under laboratory conditions. J Am Mosq Cont Assoc 21: 310-315.

Mena-Segura C, Carcavallo RU, Galíndez-Girón I, Canale D 1994. Ciclo de vida de Triatoma pallidipennis (Stal, 1872) (I) (Hemiptera: Reduviidae: Triatominae). Entomol Vect 1:33-38

Pippin WE 1970. The biology and vector capability of Triatoma sanguisuga texana Usinger and Triatoma gerstaeckeri (Stal) compared with Rhodnius prolixus (Stal) (Hemiptera: Triatominae). J Med Entomol 7: 30-45.

Rabinovich J 1972. Vital statistics of triatominae (Hemiptera: Reduviidae) under laboratory conditions. I Triatoma infestans Klug. J Med Entomol 9: 351-370.

Ramírez-Rovelo A, Gutiérrez-Martínez A, Rojas JC, Malo EA 1990. Observaciones sobre la alimentación in vitro de Triatoma mazzottii Usinger (Hemiptera: Reduviidae). Folia Entomol Mex 78: 273-274.

Ramsey JM, Ordoñez R, Cruz-Celis A, Alvear AL, Chavez V, Lopez R, Pintor JR, Gama F, Carrillo S 2000. Distribution of domestic Triatominae and stratification of Chagas disease transmission in Oaxaca, Mexico. Med Vet Entomol 14: 1930 .

Salazar-Schettino PM, De Haro-Arteaga I, Cabrera-Bravo M 2005. Tres especies de triatominos y su importancia como vectores de Trypanosoma cruzi en México. Medicina 65: 63-69.

Sosa-Jurado F, Zumaquero-Ríos JL, Reyes PA, Cruz-García A, Guzmán-Bracho C, Monteón VM 2004. Factores bióticos y abióticos que determinan la seroprevalencia de anticuerpos contra Trypanosoma cruzi en el municipio de Palmar de Bravo, Puebla, México. Sal Púb Méx 46: 39-48.

Torres-Estrada JL, Martínez-Ibarra JA, García-Perez JA 1993. Influence of sex on selecting indoor resting sites by Triatoma pallidipennis adults under laboratory and field conditions. Universidad y Ciencia 9: 44-47. 
Vidal-Acosta V, Ibáñez-Bernal S, Martínez-Campos C 2000. Infección natural de chinches Triatominae con Trypanosoma cruzi asociadas a la vivienda humana en México. Sal Púb Méx 42: 496-503.

Villegas-García JC, Santillán-Alarcón S 2001. Sylvatic focus of the American Trypanosomiasis in the state of Morelos, Mexico. Rev Biol Trop 49: 685-688.

Villegas-García JC, Santillán-Alarcón S 2004. Role of Meccus pallidipennis Stål, 1872 in the transmission of Trypanosoma cruzi to man in the state of Morelos, Central Mexico. Entomol Vect 11: 349-362.
Zárate LG 1983. The biology and behavior of Triatoma barberi (Hemiptera: Reduviidae) in Mexico. III. Completion of the life cycle, adult longevity, and egg production under optimal feeding conditions. J Med Entomol 20: 485-497.

Zeledón R, Alvarado R, Jirón JF 1977. Observations on the feeding and defecation patterns of three triatomine species (Hemiptera: Reduviidae). Acta Trop 34: 65-77

Zeledón R, Guardia VM, Zúñiga A, Swartzwelder JC 1970. Biology and ethology of Triatoma dimidiata (Latreille, 1811). II Life span of adults and fecundity and fertility of females. J Med Entomol 7: 462-469. 